\title{
La búsqueda del diálogo cultural en Sueño con menguante. Biografía de una machi de Sonia M ontecino
}

Searching for a cultural interchange in Sueño con menguante. Biografía de una machi by Sonia M ontecino

Clara María Parra Triana

Universidad de Concepción. Concepción, Chile

claraparra@udec.cl

\section{RESUMEN}

El presente acercamiento al texto de Sonia M ontecino Sueño con menquante. Biografía de una machi (1999), a las luces de los estudios de M artin Lienhard y Jorge M arcone sobre oralidad y escritura, se propone desentrañar algunos puntos que convergen en el diálogo cultural planteado por M ontecino, desde la escritura de una experiencia de vida y la construcción de una voz híbrida.

Palabras claves. O ralidad, escritura, autobiografía, diálogo cultural.

\section{ABST RACT}

This is an approach to Sonia M ontecino's text Sueño con menguante. Biografía de una machi which looks for searching on some aspects that define a cultural dialogue, showed by the author throughout a life experience writing and an hybrid voice construction. This study is developed according to $M$ artin Lienhardt and Jorge M arcone's studies all about orality and writing.

Keywords: 0 rality, writing, authobiography, cultural dialogue.

Recibido: 14-12-2007. Aceptado: 01-04-2008.

A H ETERO GEN EID AD en los productos literarios latinoamericanos no ha sido la excepción sino la norma, ello ha dado espacio a diversas formas de narrar, de crear ficción. Tales formas que buscan examinar al ser humano en su diálogo con el mundo, con la cultura, le han brindado la posibilidad de com- 
partir discursos en los que lo literario se constituye como manera de acercarse al "otro", como forma de conocimiento del mundo con diferentes propósitos. Es así como los discursos de las ciencias sociales (históricos, sociológicos, antropológicos, etc.) encuentran en la ficción la alternativa de compartir lo indagado, para así evitar caer en las clásicas descripciones desde fuera, que hacen exótica la experiencia de acercamiento y de esta manera lograr un encuentro afortunado con el otro, siempre enigmático, pero a su vez siempre presente].

Tales formas de narrar se han hecho problemáticas en la medida en que han fusionado diversas instancias discursivas, las cuales al ser revisadas desde el punto de vista crítico cuestionan las dinámicas de verosimilitud, veracidad, fidelidad y/o persecución de propósitos políticos disfrazados. D e esta forma, la inscripción de un texto dentro de un género le provee una carga conflictiva en su adhesión al capital de productos culturales y literarios de un espacio determinado. Este es el problema que comparten los textos de carácter testimonial, o mejor, los textos que poseen una base o fuente documental, y que al tener como referente una situación social del conflicto, como el desplazamiento de los grupos marginados, parecieran tener siempre una finalidad que trasciende el "simple hecho de contar una historia".

El texto de Sonia M ontecino no ha podido escapar a esta dificultad de estudio y análisis. Al ubicarse en el umbral entre el testimonio "real" de una machi (médico mapuche) y la ficcionalización del encuentro del mundo huinka (blanco o mestizo chileno) con la comunidad mapuche, el texto ha sido objeto de las más agudas críticas en cuanto al estatus autorial, ficcional, político e incluso ideológico. El texto de Susan Foote, por ejemplo, titulado "El testimonio mapuche y la literatura chilena: Carmela Romero Antivil y Sonia M ontecino en el libro Sueño con menguante. Biografía de una machi", pone en tela de juicio el uso que M ontecino hace del testimonio de Carmela Romero, una mujer de "carne y hueso" que entrega su historia de vida para que otro finja una "experiencia compartida", veamos:

La desigualdad salta a la vista: la huinka se identifica con nombre y apellido, mientras que la mapuche sólo se identifica de manera impersonal en el subtítulo como "machi". Autor: Sonia M ontecino, sujeto: una machi. Un autor de nombre y apellido y un sujeto "exótico". Esta relación está invertida en el texto ya que la narradora huinka es anónima y la machi se identifica como $C$ armela Romero Antivil (3).

\footnotetext{
${ }^{1}$ D entro de las tantas preocupaciones a que se enfrenta, no sólo la literatura sino también los mismos estudios literarios (culturales) latinoamericanos, se encuentra el hallazgo de las repuestas a la pregunta de cómo enmarcar prácticas culturales heterogéneas.
} 
Esta aguda crítica que Foote lanza al texto de M ontecino refleja una postura ante el carácter del documento; es una postura de defensa desde la revisión de la categoría autorial, del género y de las estrategias de integración de la historia de vida que hace las veces de hilo conducente del relato central de la obra. La lectura de Foote es una clara muestra del tipo de polémicas que generan las narraciones del "umbral", que llegan a ser objeto de debates sociales y de posturas de protección al otro oprimido o silenciado².

Sin embargo (y más allá de la premura "por hacer justicia"), el texto deFoote plantea una pregunta que ilumina la presente discusión: ¿Q uién es la autora del texto Sueño con menguante?Teniendo en cuenta la carga semántica de la palabra autor, como voz de autoridad, inicial mente podría resolverse el problema señalando que M ontecino se hace cargo de llevar al papel la narración de la historia de vida (más allá de la simple trascripción), que bien puede ser la biografía de la machi (escrita por otro), la autobiografía contada por Carmela Romero Antivil - la novela testimonial que M ontecino elabora sobre la base de sus experiencias de vida como antropóloga, que se da a la tarea de consignar las experiencias de los encuentros, poniéndolos en la voz de un personaje que se particulariza dentro de su comunidad, pero que al mismo tiempo y a través de su configuración dentro de la ficción habla por y desde ella3.

Para el lector no es posible pasar por alto el hecho de que M ontecino no sólo sea quien lleva la narración al papel, sino que además lo hace desde el ojo del antropólogo (el letrado) que se acerca al mundo mapuche con el fin de conocer desde la propia experiencia el espacio ignorado. Ello implica que existe una actitud de compartir la vivencia a través de lo narrado y de esto último hacia un público lector que se interese por conocer este fragmento del mundo mapuche, como lo encontramos en La voz y la huella: "No se debe olvidar nunca, sin embargo, que en todos los casos, aun en los más favorables, el discurso oral indíge

\footnotetext{
2 En este punto traemos a colación lo apuntado por 0 stria (2001) en donde resalta la proliferación de estos discursos problemáticos en sí mismos, llenos de propósitos de reivindicación y de ataque a lo hegemónico, a lo institucionalizado: “... en el plano de la literatura latinoamericana, en la que abundan los esfuerzos por recuperar en la escritura todo tipo de expresiones y discursos procedentes de la cultura oral, tanto los que provienen de la comunicación informal (popular, vulgar, rural) como las correspondientes a la oralidad cultural de los pueblos aborígenes americanos. Se trata, sin duda, de un esfuerzo, con lo excluido por el canon de la literatura y la cultura oficial, de dar testimonio de las voces ausentes en el interior de las manifestaciones culturales canónicas" (75).

${ }^{3}$ Al respecto, Paul de M an, citado por Juan M anuel Cuartas Restrepo (1999), señala: "La autobiografía (... ) parece depender de los hechos potencialmente reales y verificables de manera menos ambivalente que la ficción. Parece pertenecer a un modo de referencialidad, de representación y de diéresis más simple que el de la ficción. Puede contener numerosos sueños y fantasmas, pero estas desviaciones de la realidad están enclavadas en un sujeto cuya identidad viene definida por la incontestable legibilidad de su nombre propio" (886).
} 
na se 'petrifica' por su trascripción y se desvía de su público natural (la colectividad indígena) hacia el público elitista de los letrados" (Lienhard, 1990: 69).

De este modo, Montecino actuaría como el buen letrado (parodiando la noción del buen salvaje), que toma por su cuenta la misión de abrir las puertas de un mundo ignorado por gran parte de la sociedad chilena, la cual soslaya sus orígenes locales, como señala 0 stria:

Los chilenos, a diferencia de otros latinoamericanos, sabemos poco o nada de nuestro principal pueblo originario: el mapuche. La historia, la educación y la cultura oficiales se han encargado o bien de construir mitos (como el de la raza chilena que descien de de bravos araucanos) o bien de establecer barreras entre chilenos y mapuches. En tanto, las políticas económicas y sociales han buscado cuando no su extinción, al menos su reducción a espacios lo más apartados posible de las poblaciones chilenas o su asimilación y transculturación. Es de cir, se ha procurado hacerlos invisibles, relegándolos, en general, a los estratos más pobres y marginales de la sociedad chilena (2006: 1).

H emos de dejar de lado la evidencia del propósito socio-ideológico que persigue M ontecino, para privilegiar la revisión del texto en tanto elaboración literaria, desarrollado sobre una concepción y práctica del lenguaje, que consolida un mundo posible de encuentro con el otro y que por lo tanto se ubica como instancia para el diálogo intercultural.

\section{ETNOFICCION E INSCRIPCION DE LA ORALIDAD}

Sueño con menguante puede ser considerado aun con sus particularidades estructurales y discursivas dentro de lo que M artin Lienhard llama etnoficción: "En el contexto de las relaciones interculturales que generan los colonialismos, es la recreación 'literaria' del discurso del otro, la fabricación de un discurso étnico artificial, destinado exclusivamente a público ajeno a la cultura 'exótica' (1990: 290).

Pese a que es un texto en el que hay un esfuerzo por anclar la historia a lo documental-empírico (referencia a lugares específicos como Temuco, Rancagua - Santiago, elementos de la cotidianidad chilena, medios de transporte, por ejemplo), no deja de erigirse como una construcción de ficción en la que la autora "echa mano" de su experiencia como antropóloga para consolidar una búsqueda en la elaboración de un mundo posible mapuche, escrito en castellano para compartirlo con el público que no se halla inscrito en las dinámicas culturales de esta comunidad.

El texto está escrito sobre las bases del discurso oral que, como señala Foote: 
"No se trata de hablar por el otro o dejar hablar al otro sino de respetar la autoridad del otro para hablar sin apoderarse de su texto y reconocer que el texto oral es el texto matriz sin el cual no hay libro" (7). La oralidad en este caso (y en la etnoficción en general) es una ilusión, dado que no es posible retratarla en la escritura, pero al mismo tiempo se hace necesario tenerla presente, ya que es la vía de acceso a lo primigenio; es una manera (muy compleja) de reconocerle al grupo en cuestión su particularidad y su forma de ubicarse en el orden del mundo:

Sólo con el tiempo pude darme cuenta de que el me dijeron, dijo, dijo que le dijo, tenían sentido, y que constantemente la familia de Florencia estaba evocando a al guien que a su vez era una cita de otros más antiguos. Por eso esas conversaciones, que en el fondo eran cadenas múltiples entre guiones, eran una suerte de convocatoria a muchas personas, vivas y muertas, cuyas huellas perduraban en las palabras de la kuku y de sus hijos (M ontecino, 1999: 23).

Esta ilusión de oral idad que al canza la obra se traduce en el logro estético de incluir en la escritura una voz rural, indígena, femenina, con vivencias particulares dentro de su propia comunidad: "La palabra hablada es susceptible de evocación directa o indirecta, como discurso imaginario o pseudodiscurso, mediante procesos de trascripción, imitación o transformación de diversos componentes de la escritura en vista a crear el efecto de oralidad" (0 stria, 2001: 76). $\mathrm{H}$ istorias contadas, frases dichas en alguna parte, recordadas por al guien que las retoma y las implementa, las actualiza una y otra vez, tejiendo relaciones con otros, formando la imagen de los otros, diciendo incluso con el silencio.

La palabra en la literatura, en el sentido que le da Bajtin, es un signo pletórico de significación y de pluralidad discursiva, que en M ontecino se traduce en diversas voces de tipo histórico (dictadura, reforma, conflicto militar), mítico popular (lectura y escritura de los sueños), religioso (oraciones, cantos comunitarios); que se oponen al mundo mestizo chileno, en tanto formas de conocimiento del mundo, al mismo tiempo que cuestionan los saberes letrados y se afirman los de la tierra; de allí se observa la respuesta axiológica que se desprende dela novela: la vuelta a los orígenes para el rescate de la conciencia del pueblo chileno, de la aceptación de la diversidad como componente capital de una identidad plural, que se alimenta y fortalece en sus orígenes:

Es un estudio que no viene de los libros, no hay duda, dije asintiendo a su crítico juicio sobre la inutilidad de mis saberes letrados. Ella ha aprendido de $\mathrm{N}$ genechén. Se movía entre árboles y matorrales como si estuviera en un templo, me advirtió que anduviera con atención para no pisar ninguna hojita, ningún pasto, todos eran valiosos, cada uno tenía un poder que mis botas 
podían destruir y caminé cuidadosamente, con miedo de aplastar a al gún espíritu, porque todos tienen püllü, por eso hay que dejarlos ofrendados cuando los arrancamos, hilitos, monedas, pagándole a la tierra por lo que estamos sacando (1999: 99).

En la búsqueda de ese diál ogo cultural plural, la obra se construye como una compleja red en la que convergen tres voces narrativas, las cuales se consolidan como recursos para la inscripción de la oralidad ( $M$ arcone), en las que se da la inscripción efectiva, la citación ficcional, la construcción oral en el texto, la ilusión de oralidad, así:

1. U na primera voz que narra en tercera persona que se asemeja a una narración omnisciente o desde fuera.

2. Una segunda voz que cuenta su experiencia de entrar en contacto con el mundo mapuche, y el extrañamiento ante los usos de la comunidad que habla en la lengua de la tierra, el mapudungun.

3. Y una tercera que es la voz de C armela Romero Antivil, la machi o médico mapuche que cuenta a la instancia portadora de la segunda voz, colilonko, a manera de revisión de toda su vida, su autobiografía, desde antes de nacer hasta el momento mismo del relato.

Esta inscripción de la oralidad se entiende también como una actitud hacia la escritura, hacia el lenguaje y hacia la lengua. Pensar la ficción desdela oralidad (desde su origen) es ya de por sí una decisión estética que apunta hacia la observación de los recursos que hacen del nombrar, desde la lengua del otro, una captura y un intento de experimentar más de cerca las formas de vida y de percepción del entorno y de las figuraciones del hombre que cambia de lugar para enunciar y observar la realidad ${ }^{4}$.

El recurso utilizado para que estas cuatro historias se integren dentro del relato es la representación de la oralidad como fórmula de configuración de un mundo abierto y plural. La oralidad se deja ver en este caso como el espacio para el diálogo, para la integración y el conocimiento del otro. Como señala Jorge M arcone (1997), citando a Carlos Pacheco:

La oralidad es entendida más bien como una particular economía cultural capaz de incidir de manera sustancial no sólo en los procesos de adquisición,

\footnotetext{
${ }^{4}$ El recurso a la oralidad en la escritura contribuye a la reacción de un mundo posible, lo que hace del texto en cuestión un espacio de ficción en el que la posibilidad del encuentro de dos mundos que se rechazan en la experiencia se integren allí.
} 
preservación y difusión del conocimiento, sino también en el desarrollo de concepciones del mundo y de sistemas de valores tanto históricos como presentes (34).

D e este extrañamiento de la mujer visitante mestiza, ante el mundo primigenio que toma forma para ella gracias a la oralidad, se comprende lo que ha señalado M arcone al decir que "toda repetición es una ficción" (1997: 80). Ya que ni la huinka, ni Carmela, ni el narrador omnisciente, ni Montecino, se encuentran allí tal cual, siendo la reescritura una elaboración de la voz (oral) del otro, lo interesante aquí es ver esa dinámica como propuesta de revisión para la entrada a un mundo enmarcado por la diferencia.

La oralidad es la clave de acceso para comprender el orden del mundo mapuche, que al mismo tiempo provee de puntos de confrontación con los discursos letrados. Esta inscripción de oralidad no es sólo la ficcionalización o imitación de las marcas orales (aunque sal ta a la vista su inclusión) sino también es el evento gracias al cual crean las relaciones identitarias del pueblo de codificación particular no occidentalizado: "¿qué cosa tan tremenda las separaba de esa manera? La envidia había dicho Carmela, hablan mal de mí, me calumnian; pero no podía entender qué significaba eso entre ellos, ¿qué dirían deCarmela?" (M ontecino, 1999: 104) (el énfasis es mío).

N uestros pueblos indígenas, en las que la palabra oral aún conserva su valor, lo dicho o lo no dicho, la referencia a la palabra de otros, a las historias de lo que otros hicieron y/o presenciaron posee una autoridad suficiente para dar crédito a las vivencias, que al pasar de uno a otro se convierte en sabiduría común, que alimenta su conciencia colectiva debido a que, como apunta N ila Vigil (2004), las culturas indígenas son culturas de la argumentación ${ }^{5}$.

\section{BIOGRAFIA Y AUTOBIOGRAFIA}

Aunque se subtitula Biografía de una machi, el texto oscila entre el discurso biográfico y el autobiográfico, por cuanto se instal a desde su argumento en una mirada al otro y una revisión que el yo hace de sí mismo. Por lo tanto, y acudiendo a la alocución de las voces creadas dentro de la ficción, Sueño con menguante narra tres historias que se fusionan en una cuarta:

\footnotetext{
5 Para complementar esta acotación, encontramos como ejemplo el estudio de Vigil sobre los sufijos que en quechua se usan para el manejo de la información "de oídas": "En quechua, los habitantes distinguen si la información que dan es de primera mano, o de oídas; si se conjetura algo o si se corrobora lo dicho por el oyente. Así morfológicamente hay marcas para distinguir entre: testimonial directo, testimonial indirecto, conjetural y corroborativo" (2004: 195).
} 
1. La historia dela antropóloga queescribe sobrelavida de una médica mapuche.

2. La historia de una mujer chilena mestiza que cambia su existencia gracias al contacto con el mundo mapuche.

3. La historia de cómo C armela Romero Antivil recibe de sus ancestros la sabiduría de la tierra, de hacer remedios, de curar males, y de su condición particular en la comunidad a la que pertenece, en la quelos códigos trascendentales mítico-religiosos se integran a la cotidianidad del pueblo y consolidan su particular visión del mundo.

4. Y la historia de la búsqueda de la identidad chilena, que realiza un viaje a sus orígenes y encuentra en la fusión de los mundos la seguridad y el alivio de pertenecer a un espacio y a una cultura que lucha por mantenerse desde su diferenciación en su lengua, sus códigos y sus pactos con la tierra.

La primera instancia ficcional puede ser considerada dentro del género documental-empírico, coherente con la segunda parte titulada "C uaderno de te rreno", en dondese compilan los mitosy creencias vernáculas, junto con saberes de la tierra, llevados al espacio de la "praxis vital". Al ubicarse el texto en este plano, ha generado el problema señalado al principio de la presente discusión, sobre la utilización arbitraria del testimonio de una informante indígena, para arrebatarle la voz. Por supuesto, el texto tieneun origen documental, pero dadas las formas de presentar la ficción, dado el cúmulo de voces evaluadoras del mundo que convergen al interior del texto, se haceinsoslayable la percepción de su búsqueda estética, que rebasa lo testimonial. D igamos que este primer nivel (relación antropóloga-machi) ostenta ese carácter de rescate y de evidencia de una situación etno-social problemática de la identidad de la nación que, en niveles posteriores, se consolida como una toma de posición ético-estética:

N os quedamos toda la tarde con Rosaria, toda la tarde como adheridos a esa mujer que recordaba mi infancia, quetenía gestos de mi propia abuela, toda la tarde asomados a un tiempo lejano que asíamos con sus relatos sobre la guerra con los huinkas, asomados a una historia que también era la nuestra, pero cuya versión mapuche recién conocíamos por la anciana que al lado del fogón vigilaba la tetera y dirigía la perfecta ronda de mates que bebimos hasta que asomó el crepúsculo (39).

Al soltar las amarras que sujetan el texto a lo documental, emerge la segunda historia, la cual hace las veces de gozne entre lo estrictamente testimonial y la búsqueda estético-ideológica. La constante referencia a los sueños, haber soñado con Carmela, al mismo tiempo de la recepción del llamado, la concepción del sueño divino (de $\mathrm{N}$ genechen), plantea la unión de dos pueblos negada por la diferenciación: 
Te soñé, dijo de pronto (... ) pero no me conociste; ibas muy ocupada recogiendo unas piedras negras, oscuras como la noche, te hablé pero no entendías el mapuche, colilonko, te dije, mari mari lamgnem, te dije, chum leimi kai te dije. Seguiste empeñada en mirarte en esas piedras, eran como un espejo de la noche y tú te reflejabas. El corazón se me encogió. ¿Sería posible que nuestros sueños se cruzaran? $\mathrm{N}$ o me atrevía a decirle que en el tren yo había soñado con ella en esa misma montaña (95).

El mundo de los sueños (mundo posible ficcionalizado) se consolida como un punto deencuentro del mundo mapuche (no mestizo) con el chileno (mestizo). Es un espacio en el que el diálogo y la comprensión son posibles, en donde no hay oposición entre el letrado y el no letrado, sino que hay un complemento del uno con el otro como herramienta de apertura para el no mapuche; no es la utilización de un discurso para hacer las veces de redentor de un grupo periférico.

La autobiografía, como señala Cuartas R estrepo (1999), citando y releyendo a Paul de $\mathrm{M}$ an, es el lugar en donde convergen el autos, el bios y la grafé, para dar cuenta de una de las formas como el individuo se representa a sí mismo, veamos:

... el autos, el biosy la grafé, centrándose el análisis del primero en la conexión entre el texto y el sujeto, viendo de qué manera un texto representa a un suje to, en otras palabras, al Yo que ha vivido se le añade un segundo Yo creado en la experiencia de la escritura. Entendiendo la autobiografía en un segundo sentido (bios) como reconstrucción de una vida, como forma de comprensión de los principios organizativos de la experiencia. La contemplación de la grafé, por su parte, se centra en los problemas del lenguajey del sujeto, dosformas de desapropiación del Yo consustanciales a la autobiografía (882).

D e esta manera, si pensamos en Sueño con menguante como una novela (¿biográfica? ¿autobiográfica?), nos preguntamos ¿de quién es la vida que se narra? ¿A quién se privilegia? Ese bi os za quien se refiere exactamente? Sin lugar a dudas es el recorrido por la vida de Carmela Romero Antivil un ser escogido dentro desu pueblo (escogido por las divinidades), para curar las enfermedades del cuerpo y del alma, también escogida por la autora real del texto para contar la historia de la comunidad mapuche, tanto en relación con la cultura chilena como en su percepción interna del modus vivendi. Es la vida de Carmela la que desata el efecto del reflejo de las dos vidas que se cruzan para dar cuenta de la escisión cultural interna que sufre la "raza chilena".

La mirada a sí mismo, al Yo se realiza en Sueño con menguante por partida doble: Carmela se mira a sí misma, y a través de ella se ve la historia de su comunidad en los dobles traspasos de la metrópoli al valle; se mira la colilonko en relación a Carmela, a las distancias culturales que las diferencian, a los pun- 
tos idílicos (los sueños) que las unen en la grafé, la escritura de los sueños; porque si Carmela adquirió conciencia de sí misma como machi a través de los sueños y de "escribir" en los sueños dela huinka, así mismo éstaúltima adquiere conciencia en la mirada y la escritura del otro y de esa manera puede entenderse a sí misma y a su entorno diferenciador.

La salida que plantea el texto de M ontecino en cuanto toma de posición, es la de la unificación complementaria de las dos grandes voces culturales que integran la nación. D esde Sueño con menguante como texto de ficción, el encadenamiento de las voces desemboca en el planteamiento de la utopía, en la que el regreso a los orígenes, no como vuelta al pasado, sino como revisión para virar hacia el futuro, resuelve el problema de la orfandad cultural que particulariza al pueblo chilen $0^{6}$.

\section{CONCLUSION}

A lo largo de la presente revisión pudimos ver que el texto de Montecino se integra de forma cabal a los textos híbridos de la literatura latinoamericana que, dentro de sus propósitos capitales, ostenta la particularidad de la pluralidad de voces sociales e ideológicas que se constituyen en el principal valor estético de los nuevos discursos literarios. A pesar de los posibles debates que genera el punto desde el cual parte la narración, su ubicación dentro del plano ficcional estético se hace insoslayable; sus efectos en el sentido empírico se retiran para dar paso al recurso de las distintas voces, a las distintas historias, a la inscripción de la oralidad como forma de expresión vernácula para recrear, a partir de experiencias de vida, la voz híbrida que se ubica en el espacio de la identidad del pueblo chileno, el cual revisita sus orígenes no con una mirada paternal ista, sino con una visión de conciencia histórica que reconoce la diferencia y vive en pluralidad a partir de ella.

\section{REFERENCIAS}

Cuartas Restrepo, Juan M anuel. 1999. "Jean Jacques Rousseau y Friedrich N ietzsche, Autobiografías comentadas", en T hesaurus Boletín del Insituto Caro y Cuervo 3.

Foote, Susan. s/f. "El testimonio mapuche y la literatura chilena: Carmela Romero

\footnotetext{
${ }^{6}$ Esto último se relaciona directamente con el trabajo de M ontecino (1991) sobre la identidad chilena, M adres y huachos, en la que la autora plantea la carencia de padre del pueblo chileno y el refugio en la madre (madre tierra, patria, etc.).
} 
Antivil y Sonia M ontecino en el libro Sueño con menguante, biografía deuna machi". Disponibleen http://www2.udec.d/ -docliter/mecesup/articulos/foote.pdf [Acceso: 29.04.2008].

Lienhard, M artin. 1990. La voz y la huella. Escritura y conflicto étnico-social en América Latina (1492-1988). Ciudad de la H abana: Casa de las Américas.

M arcone, Jorge .1997. O ralidad escrita. Sobre la reivindicación y reinscripción del dis curso oral. Lima: Fondo Editorial de la Pontificia U niversidad C atólica del Perú.

M ontecino, Sonia. 1991. M adres y huachos. Alegorías del mestizaje chileno. Santiago, Chile: Cuarto Propio, CEDEM .

$--\ldots-\ldots-$. 1999. Sueño con menguante. Biografía de una machi. Santiago, Chile: Editorial Sudamericana.

Ostria González, M auricio. 2001. "Literatura oral, oralidad ficticia”, en Estudios Filológicos 36, pp. 71-80.

----------. 2006. "En busca del otro (mapuche) que somos en tres novelas chilenas contemporáneas", en JALLA 2006. Jornadas Andinas de Literatura Latinoamericana. Bogotá: U. de los Andes, U . N acional de Colombia, P.U. Javeriana, Pensar. Edición en CD ROM .

Vigil, Nila. 2004. "Pueblos indígenas y escritura", en Rostrosy fronteras dela identidad. Garbarini, Carmen Gloria y Samaniego, M ario (comp.). Temuco: Universidad Católica deTemuco. 